\title{
Perigo do movimento antivacina: análise epidemio-literária do movimento antivacinação no Brasil
}

\author{
Danger of the antivaccine movement: epidemio-literary analysis of the anti-vaccination \\ movement in Brazil
}

Peligro del movimiento antivacunas: análisis epidemiológico literario del movimiento antivacunación en Brasil

Renata Paula Lima Beltrão ${ }^{1 *}$, Alba Angélica Nunes Mouta ${ }^{1}$, Nickolas Souza Silva ${ }^{2}$, Jocerone Emerson Nogueira Oliveira ${ }^{1}$, Ilvanete Tavares Beltrão ${ }^{3}$, Camila Maila Fontinele Beltrão ${ }^{3}$, Sâmara Moreira Fontenele ${ }^{4}$, Augusto César Beltrão da Silva ${ }^{3}$.

\section{RESUMO}

Objetivo: Analisar a literatura sobre o movimento antivacinação e fazer as possíveis relações com os dados epidemiológicos da cobertura vacinal brasileira. Revisão bibliográfica: Movimentos contrários as imunizações sempre existiram desde a origem das vacinas, no entanto, na última década esses movimentos vem ganhando força e um maior espaço nas mídias digitais. Isso se deve a crescente influência que a internet e as redes sociais exercem sobre a vida dos usuários, visto que muitas campanhas de antivacinação utilizaram esse meio para perpetuar notícias contrárias as vacinas. Foi observada uma grande redução na cobertura vacinal brasileira nos últimos cinco anos, os dados mostram que todas as vacinas ofertadas tiveram redução de aplicação no período observado. Considerações finais: 0 ressurgimento de doenças que antes eram controladas vem preocupando profissionais de saúde de todo o mundo. Sendo necessário a criação de estratégias que diminuam a influência desse movimento e reforce a importância da imunização.

Palavras-chave: Movimento contra vacina, Imunização, Rede social.

\begin{abstract}
Objective: To analyze the literature on the anti-vaccination movement and make possible relationships with epidemiological data on Brazilian vaccine coverage. Literature review: Movements against immunizations have always existed since the origin of vaccines, however, in the last decade these movements have been gaining strength and greater space in digital media. This is due to the growing influence that the internet and social networks have on users' lives, since many anti-vaccination campaigns have used this medium to perpetuate news that is contrary to vaccines. A great reduction in the Brazilian vaccine coverage was observed in the last five years, the data show that all vaccines offered had a reduction in application in the observed period. Final considerations: The resurgence of diseases that were previously controlled has been worrying health professionals around the world. It is necessary to create strategies that reduce the influence of this movement and reinforce the importance of immunization.
\end{abstract}

Keywords: Anti-vaccination movement, Immunization, Social networking.

\footnotetext{
1 Universidade Federal do Delta do Parnaíba (UFDPAR), Parnaíba - PI. *E-mail: rplbeltrao@gmail.com

2 Universidade Federal do Ceará (UFC)

${ }^{3}$ Instituto de Educação Superior do Vale do Parnaíba (IESVAP)

${ }^{4}$ Universidade Maurício de Nassau (UNINASSAU)
} 


\section{RESUMEN}

Objetivo: Analizar la literatura sobre el movimiento antivacunación y hacer posibles las relaciones con los datos epidemiológicos sobre la cobertura de la vacuna brasileña. Revisión bibliográfica: Los movimientos contra las inmunizaciones siempre han existido desde el origen de las vacunas, sin embargo, en la última década estos movimientos han ido ganando fuerza y un mayor espacio en los medios digitales. Esto se debe a la creciente influencia que Internet y las redes sociales tienen en la vida de los usuarios, ya que muchas campañas contra la vacunación han utilizado este medio para perpetuar noticias que son contrarias a las vacunas. Se observó una gran reducción en la cobertura de la vacuna brasileña en los últimos cinco años, los datos muestran que todas las vacunas ofrecidas tuvieron una reducción en la aplicación en el período observado. Consideraciones finales: El resurgimiento de enfermedades previamente controladas ha preocupado a los profesionales de la salud de todo el mundo. Es necesario crear estrategias que reduzcan la influencia de este movimiento y refuercen la importancia de la inmunización.

Palabras clave: Movimiento anti-vacunuación, Inmunización, Red social.

\section{INTRODUÇÃO}

A vacinação é um meio eficaz para prevenção de doenças e agravos e, por décadas, considerada uma das principais estratégias da saúde pública, sendo uma maneira de reduzir e/ou erradicar doenças, como a varíola. Segundo a Organização Mundial da Saúde (OMS) (2013), a vacinação previne de dois a três milhões de óbitos anualmente no mundo. No Brasil, as primeiras campanhas de vacinação datam do ano de 1804, e naquele momento histórico, possuíam o caráter obrigatório e compulsório, com finalidade de combater a febre amarela urbana, a varíola e a poliomielite. A população criou um sentimento negativista acerca da administração vacinal, sustentando a lenda popular de que as vacinas eram pouco seguras e/ou armas biológicas criadas pelo governo para controle populacional. Os mitos sobre a real função das vacinas são motivos de diversos conflitos religiosos, políticos e legais (FRANÇA ISX, et al., 2009; GASPARINI R, et al., 2015; HUSSAIN A, et al., 2017; D’ALÒ GL, et al., 2019).

Em países como a Inglaterra e Estados Unidos da América (EUA), foram criadas Ligas Antivacinação para perpetuar a liberdade dos pais sobre a decisão de se seus filhos deveriam ou não ser imunizados. No Brasil, citamos a Revolta da Vacina, em 1904, que foi um levante popular dos moradores do Rio de Janeiro contrários às ações governamentais, que tornavam obrigatória a vacinação e puniam aqueles que se negassem. Durante séculos, os benefícios do processo de imunização foram pouco questionados; mas um artigo publicado pelo médico Andrew Wakefield, em 1998, na revista "The Lancet", afirmando que a vacina contra sarampo, caxumba e rubéola tinha relações com o desenvolvimento de autismo, reacendeu e fortaleceu o movimento (SUCCI RCM, 2017; HUSSAIN A, et al., 2018).

A presença de efeitos colaterais em uma pequena parte da população vacinada, o não convívio da geração de pais com as doenças que são prevenidas e, atualmente, a disseminação virtual de notícias falsas, incentivam a não adesão ao calendário vacinal, expondo a população ao ressurgimento de mazelas como o tétano, difteria e coqueluche.

O movimento antivacinação, ou antivaccinators (em inglês), prega que as vacinas trazem mais malefícios do que benefícios e buscam por meio de crenças ou emoções, com embasamento filosófico, espiritual e/ou político, provar que o uso de vacinas ameaça a população. Dentre os malefícios citados pelo movimento anti-vacina, são levantadas as seguintes teorias: as vacinas causam autismo, o excesso de vacinas pode levar há uma sobrecarga imunológica, as vacinas são uma tentativa de realizar um controle populacional e que as vacinas contém metais pesados em suas formulações (SANTOS VLC e SANTOS JE, 2017; BRASIL, 2018).

Um outro fator que contribuiu para a estruturação do movimento antivacina foi a revolução da informação. As redes sociais permitem a criação de novos espaços de relacionamento, técnicas de ensino e aprendizagem, formas de discutir política e de entretenimento. Cerca de $43 \%$ dos usuários das redes 
sociais afirmaram fazer uso de duas horas diárias nesses meios, sendo, portanto, uma grande exposição a diversas fontes de informação, muitas delas não confiáveis, mas que por serem veiculadas por amigos ou por pessoas famosas, acabam influenciando na forma de pensar dos usuários (SANTOS VLC e SANTOS JE, 2017; SUCCI RCM, 2017).

Nesse contexto, algumas celebridades como Charlie Sheen, Jim Carrey, Jenny McCarthy, Oprah Winfrey e Rob Schneider passaram a defender a ideia antivacinação, utilizando suas redes sociais e programas de televisão para veicular informações contrárias a prática (LOWE T, 2019).

A queda na cobertura vacinal nacional assusta estudiosos e profissionais da área, acentuando a necessidade de conhecer e intervir em quaisquer circunstâncias que reforcem essa realidade. Segundo um estudo realizado em 2009 no município de Campina Grande - PB, que avaliou as dificuldades enfrentadas pelos enfermeiros em cumprir a meta de vacinação, $26 \%$ do total de casos foi por resistência vacinal dos pais, influenciando negativamente o número final da cobertura vacinal, e consequentemente, afetando a lógica do "efeito guarda-chuva", que é a proteção indireta do indivíduo não vacinado devido à vacinação de outrem, isso se deve à não transmissão do patógeno pelos indivíduos vacinados para os não vacinados (FRANÇA ISX, et al., 2009).

Dentro da relevância da temática, este trabalho tem como objetivo realizar uma análise de estudos científicos por meio da realização de uma revisão de literatura sobre o movimento antivacinação, visando perceber sua abrangência e magnitude no mundo, mas principalmente no cenário do território brasileiro, para isso, fazendo uso da análise de estratégias midiáticas utilizada pelos opositores da vacina e definir possíveis relações entre esse movimento com os dados epidemiológicos vacinais nacionais.

\section{REVISÃO BIBLIOGRÁFICA}

\section{Movimento anti-vacina nas mídias sociais}

A oposição organizada à vacinação é um crescente fenômeno global. Em uma busca simples no Google, o website mais visitado do mundo e que funciona como uma plataforma de busca popular, o termo "antivaccination" oferece 135.000 resultados e o termo "antivacinação" alcança 110.000. O movimento é mais sólido no Norte da Europa e nos EUA, mas tem ganho adeptos brasileiros, os argumentos e crenças dos grupos antivacinação não sofreram tantas modificações no último século e se baseiam na crença de que as vacinas são inseguras e ineficientes (RADZIKOWSKI J, et al., 2016).

Em contrapartida, os veículos de informações sempre representaram uma ferramenta da comunicação em saúde, como meio de alcance dos provedores de cuidados de saúde, aos pacientes e comunidades. A capacidade de dissipar informações mudou de características, aumentou em efetividade e velocidade nas últimas décadas. A revolução na informação, amplia o objetivo e as vias de discussões sobre saúde; não mais focando exclusivamente na comunicação de surtos e disseminação de notícias oficiais.

A internet reformula o fluxo comunicativo e permite, entre outras coisas: a) o compartilhamento rápido de opiniões e informações, sem exigir comprovação científica; b) a organização comunitária em grupos por afinidade, entre indivíduos que nunca se conheceram fisicamente; c) a criação de redes sociais e de empoderamento individual e grupal; e d) o ativismo político, religioso e cultural. Diante disso, o alcance das mídias sociais é identificado como uma das principais razões para o crescente receio dos pais sobre as vacinas recomendadas na infância (LEASK J, 2015, RADZIKOWSKI J, et al., 2016; SUCCI RCM, 2017; TUSTIN JL, et al., 2018).

Os militantes do movimento antivacina promovem a si mesmos como defensores da transparência da informação pública e da escolha individual, e localizam sua retórica em temas polêmicos como a ameaça do excessivo controle governamental, manipulação para o lucro e as supostas afirmações de que as vacinas causam efeitos adversos que são ocultados pelo governo. Esses grupos são de difícil controle e atuam tentando influenciar pais, usando a lógica de que quanto mais o assunto está na mídia, mais medo gera na população, e consequentemente leva a redução das imunizações (LEASK J, 2/015, SUCCI RCM, 2017; TUSTIN JL, et al., 2018). 


\section{Fatores que influenciam na recusa da vacina}

Os fatores de influência na hesitação ou recusa vacinal são pessoais, políticos e socioculturais, complexamente formulados (KUPFERSCHMIDT K, 2017). Succi RCM (2017), relata que população: a) desconhece a verdadeira necessidade da imunização, sua segurança e eficácia; b) alimenta o medo de possíveis eventos adversos; c) possui experiências prévias negativas na saúde; e d) desconfia da seriedade da indústria de vacinas e do sistema de saúde.

O mais preocupante é que esses grupos são compostos, principalmente, por pais. Alguns podem expressar uma antipatia implícita à intervenção médica, com uma predileção por modos naturais ou alternativos de prevenção e tratamento de doenças. Em julho de 2019, um caso julgado pelo Tribunal de Justiça de São Paulo (TJ-SP) ganhou destaque nacional. O TJ-SP determinou que um casal do município de Paulínia vacinasse o filho de três anos.

Os genitores e representantes legais do menor apresentaram como conjunto de justificativas: o fato de a criança não estar na escola e, portanto, estar "longe de riscos de infecções", a adoção da "filosofia vegana" e a posição contrária a "intervenções invasivas". Não vacinar é uma demonstração de um conjunto de valores. Outros ativistas incluem cidadãos em geral, profissionais de saúde e provedores de terapias alternativas (LEASK J, 2015; NEVES J, 2019).

Vários fatores socioeconômicos e educacionais podem estar relacionados com a adesão do movimento anti-vacina, Vasconcellos-Silva PR (2015) elucida em sua publicação que o padrão das crianças subimunizadas é de ser filhos de mães jovens e solteiras, com baixa escolaridade e residentes em comunidades pobres nas adjacências de grandes centros. Em contraste, as crianças absolutamente não imunizadas eram filhos de mães casadas, com alto nível de escolaridade, que residem em vizinhanças com renda acima da média nacional e contam com amplo acesso aos meios de comunicação de massa.

Em indivíduos críticos, o Modelo de Crenças em Saúde deveria determinar a tomada de decisão quanto a vacinação. Em termos matemáticos, a decisão de vacinar é equilibrada pelo risco compreendido de adquirir uma doença evitável pela vacinação e pelo risco percebido de complicações que esta imunização pode apresentar. Entretanto, o estudo que recentemente investigou a confiança dos pais nas vacinas recomendadas na infância nos EUA descobriu que tanto os pais resistentes quanto os que aceitam as vacinas têm dúvidas, preocupações ou percepções errôneas sobre a imunização. A maioria dos pais referiu buscar informações sobre a segurança das vacinas antes de aplicá-las nos filhos e reconheceu a internet como uma relevante fonte de informação, mas não necessariamente em sites técnicos e idôneos (TUSTIN J, et al., 2018).

\section{Programa Nacional de imunização (PNI)}

O PNI brasileiro é referência mundial, sendo pioneiro na disponibilização de vacinas de modo universal. Apesar disso, o principal responsável pela adesão popular à vacinação foi o bom uso da mídia: optou-se por um linguajar simples e apelativo, respeitando a diversidade étnica; explorou-se todos os possíveis meios, como a televisão, o rádio, os jornais, as revistas, cartazes e panfletos; figuras de sucesso e considerados heróis nacionais foram elencados nas campanhas, como Airton Senna; pessoas que sofreram com as doenças a serem prevenidas pela vacinação foram levadas à público para mostrar sequelas e complicações deixadas pelas falta de vacinação; e criou-se símbolos populares, como o Zé Gotinha. O resultado foram coberturas vacinais infantis acima de $95 \%$ e o controle de doenças imunopreveníveis (CRUZ A, 2017; SATO APS, 2018)

A partir de 2016, essas coberturas têm declinado cerca de 10 a 20 pontos percentuais (Gráfico 1). Este evidencia a quantidade de doses aplicadas das vacinas: BCG, Hepatite B, Tríplice bacteriana (difteria, tétano e coqueluche) e Tríplice viral no período de 2015 a 2019. É nítida a redução do total de doses aplicadas nas vacinas contra a Hepatite B, já os dados referentes a BCG e a Tríplice bacteriana mostra uma redução moderada. No entanto, discordando com os dados de redução da maioria das vacinas observadas no período, notamos um aumento significativo das doses aplicadas da Tríplice viral. 
Gráfico 1 - Doses aplicadas por ano segundo os imunobiológicos.

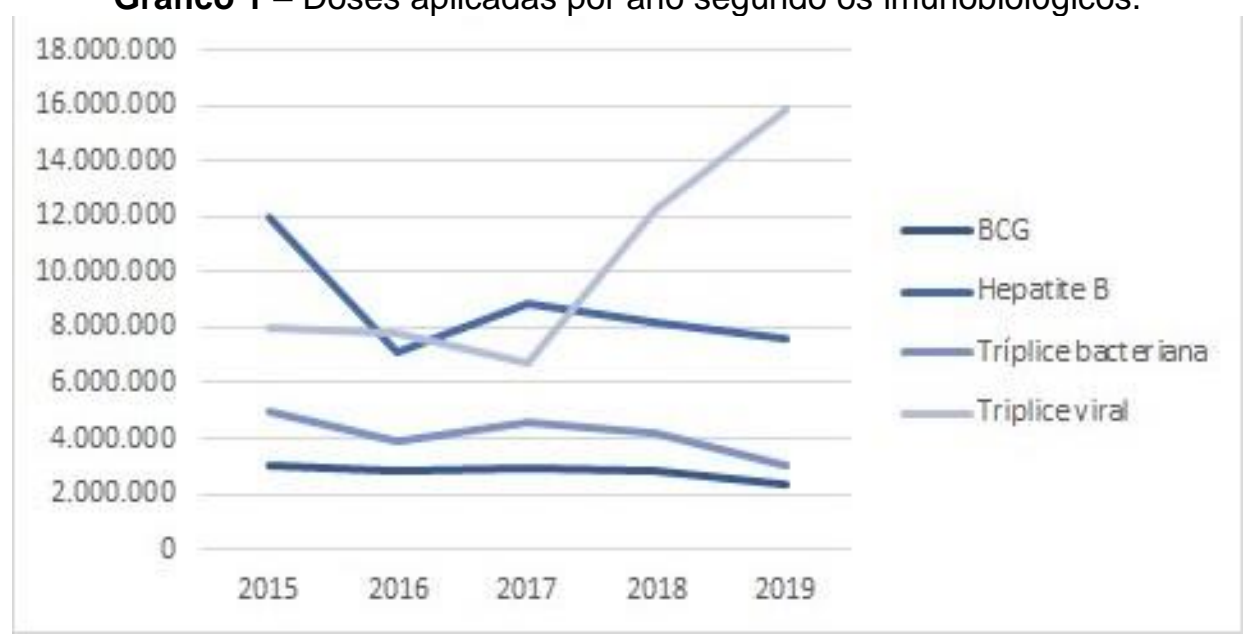

Fonte: Beltrão RPL, et al., 2020. Adaptado de Ministério da Saúde, 2019.

\section{Cobertura vacinal dos últimos 5 anos de acordo com o Ministério da Saúde (MS)}

Em 2018, outra constatação assustou os profissionais da saúde, sete das oito vacinas obrigatórias para crianças não bateram a meta de cobertura, apenas a Bacilo de Calmette-Guérin (BCG) alcançou o valor de doses esperado. Nos últimos cinco anos, foi observado uma redução na cobertura vacinal de quase todas as vacinas disponibilizadas pelo Sistema Único de Saúde (SUS), como pode ser observado na tabela abaixo (NEVES J, 2019). Ver-se que das 22 vacinas citadas no estudo, todas apresentaram redução da cobertura vacinal nos 5 anos analisados, variando entre 7 e $71 \%$; a média de redução de cobertura está entre 40 e $55 \%$. Dentre as vacinas com menor taxa de redução estão: dTPa gestante (7\%), Febre Amarela (14\%) e Duplo Adulto e tríplice acelular gestante (32,6\%). A justificativa para essa maior adesão está no fato de duas dessas vacinas fazerem parte da caderneta vacinal da gestante, refletindo a assistência pré-natal, com um maior número de consultas/mês que a população não-gestante (Tabela 1).

Tabela 1 - Cobertura vacinal brasileira nos últimos cinco anos.

\begin{tabular}{|c|c|c|c|c|c|}
\hline Imunobiológicos & 2015 & 2016 & 2017 & 2018 & 2019 \\
\hline $\mathrm{BCG}$ & 105,08 & 95,55 & 97,12 & 97,72 & 52,95 \\
\hline DTP & 96,9 & 89,53 & 84,02 & 87,31 & 49,86 \\
\hline DTP REF ( 4 e 6 anos) & & 2,73 & 2,81 & 1,93 & 1 \\
\hline dTpa gestante & 44,97 & 33,81 & 42,36 & 63,06 & 41,97 \\
\hline Dupla adulto e tríplice acelular gestante & 45,57 & 31,53 & 34,56 & 47,02 & 30,73 \\
\hline Febre Amarela & 46,31 & 44,59 & 46,46 & 58,4 & 39,91 \\
\hline Hepatite A & 97,07 & 71,58 & 83,05 & 82,16 & 52,09 \\
\hline Hepatite B (menores de 30 dias) & 90,93 & 81,75 & 85,2 & 86,73 & 48,33 \\
\hline Hepatite B & 97,74 & 105,19 & 86,29 & 92,91 & 55,93 \\
\hline Meningococo $\mathrm{C}$ & 98,19 & 91,68 & 87,04 & 87,5 & 53,66 \\
\hline Meningococo $\mathrm{C}$ (1ㅇr ref) & 87,85 & 93,86 & 82,13 & 79,72 & 55,16 \\
\hline Penta & 96,3 & 89,27 & 83,78 & 87,1 & 49,73 \\
\hline Pneumocócica & 94,23 & 95 & 91,56 & 93,43 & 54,43 \\
\hline Pneumocócica(1ํ ref) & 88,35 & 84,1 & 79,66 & 80,02 & 50,5 \\
\hline Poliomielite & 98,29 & 84,43 & 84,27 & 88,17 & 51,54 \\
\hline Poliomielite(menores de 4 anos) & & & 0,62 & 0,47 & 0,19 \\
\hline Poliomielite( $1^{\circ}$ ref) & 84,52 & 74,36 & 78,06 & 71,9 & 45,89 \\
\hline Rotavírus Humano & 95,35 & 88,98 & 84,65 & 89,76 & 52,47 \\
\hline Tetra & 77,37 & 79,04 & 36,86 & 32,46 & 22,46 \\
\hline Tríplice Bacteriana & 85,78 & 64,28 & 74,29 & 67,49 & 38,7 \\
\hline Tríplice Viral D1 & 96,07 & 95,41 & 90,85 & 91,89 & 57,19 \\
\hline Tríplice Viral D2 & 79,94 & 76,71 & 76,45 & 76,49 & 48,37 \\
\hline
\end{tabular}

Fonte: Beltrão RPL, et al., 2020. Adaptado de Ministério da Saúde, 2019. 
Além disso, a adesão vacinal da Febre Amarela pode ser motivada pelo surto da doença que ocorreu entre 2018 e 2019 no Brasil, com um registro de 36 casos, 8 deles evoluindo para óbito. Em contrapartida, as vacinas que registraram as maiores reduções estão: DTP 4 a 6 anos (63,5\%), Poliomelite 4 anos (69\%) e a Tetra (71\%), coincidindo com a faixa etária entre 0-6 anos, alvo principal do movimento antivacina (BERNARDO A, 2019).

As taxas de imunização estão caindo em vários países, e as doenças evitáveis por imunização voltaram a causar grandes surtos, mesmo nos países desenvolvidos. Nos EUA, em 2014, houve relato de 644 casos de sarampo - três vezes mais casos do que no ano anterior. Tal fato chamou a atenção dos órgãos governamentais, já que a doença era tida como erradicada no país desde 2000. O Brasil teve um surto de Sarampo em 2018, após 2 anos da certificação de erradicação do vírus concedido pela Organização Pan americana de Saúde (OPAS). Os estados de Pernambuco e Ceará foram os mais atingidos, coincidentemente após uma queda de imunização. Esse surto fez o país perder a certificação. $O$ ressurgimento do sarampo tem sido associado a um aumento no número de pais que se recusam a vacinar seus filhos (HORNE Z, et al., 2015; KUPFERSCHIMIDT K, 2017).

O convívio com a doença e a percepção palpável de casos no território brasileiro pode ter influenciado diretamente na grande tendência de recuperação da Tríplice viral, vacina que previne sarampo, caxumba e rubéola, que dobrou sua cobertura em 2 anos, como o apresentado no gráfico abaixo:

\section{Impacto do movimento antivacina e estratégias para combatê-lo}

Diversos países estão passando por problemática semelhante. Em 2017, a Itália notificou um caso de uma criança de 10 anos com tétano, sendo o primeiro caso da doença em 30 anos no país. Também em 2017, nos EUA, uma criança de 6 anos contraiu tétano e os custos de seu tratamento ultrapassou 1 milhão de dólares, sendo que neste país o preço para a aplicação da dTPa (vacina que protege contra coqueluche, tétano e difteria) é cerca de 30 dólares. Casos como esses exemplificam o volumétrico custo em saúde que é determinado pelas falhas na cobertura vacinal (BERNARDO A, 2019).

Laurent-Ledru V, et al. (2011) afirma que o sucesso sustentável dos programas de vacinação somente consegue ser mantido com o contínuo progresso das campanhas de imunização, a partir de esforços conjuntos de todos os interessados, incluindo o poder público, profissionais da saúde e, principalmente, os usuários dos serviços de saúde. Demonstrando a veracidade dessa colocação, podemos analisar o ano de 2014, que apresentou pico na aplicação das vacinas. Este fato coincide com pacto entre os gestores de saúde por meio do Contrato Organizativo de Ação Pública da Saúde (COAP), que buscou, por meio de ações compartilhadas, entre outras coisas, atender as propostas do PNI (BRASIL, 2015).

Por isso, é dever dos órgãos e profissionais de saúde procurar meios que visem uma conscientização da população sobre os benefícios que a imunização em massa apresentará para a sociedade. D'Alò GL, et al. (2017) garante que uma estratégia plausível é desenvolver um novo plano de comunicação de risco que, ao invés de evidenciar os possíveis eventos adversos, complicações da doença e sua incidência, utilize de ferramentas e vocabulário amplamente inteligíveis, a fim de responder claramente às questões dos usuários de serviços de saúde. Também é necessário que as mídias sociais sejam usadas para a divulgação da importância das vacinas, como dito pelo geógrafo brasileiro Milton Santos, para que o processo de aprendizagem seja eficaz, é necessário que seja realizado de acordo com as condições do meio em que as pessoas estão inseridas. Ou seja, da mesma forma que a campanha antivacina utiliza das mídias digitais para influenciar os usuários dessas ferramentas, estas também devem ser usadas para a conscientizar a população sobre a importância da vacinação (GUIMARÃES K, 2017).

Reconhecendo o acesso à informação e a preocupação crescente dos pais sobre a vacinação, o MS (2018) ratifica importância de reconhecer falsas informações, as chamadas fakes news. Algumas dessas informações errôneas são pontuadas pelo MS, como: "vacinas causam autismo", "as vacinas contêm mercúrio, que é perigoso", "aplicar mais de uma vacina ao mesmo tempo em uma criança pode aumentar o risco de eventos adversos prejudiciais", aplicar mais de uma vacina por vez pode sobrecarregar seu sistema imunológico", e "as doenças evitáveis por vacinas estão quase erradicadas em meu país, por isso não há 
razão para me vacinar" (BRASIL, 2018). Outra estratégia utilizada por órgãos governamentais e nãogovernamentais é dificultar o acesso às informações negativas sobre a vacina. Devido às volumosas campanhas utilizando como meio de propagação as redes sociais, ao buscar o tema "antivacina" no instagram e no facebook, eles abrem um alerta sobre os perigos de informações não confiáveis e oferecem a opção do usuário ser redirecionado para um página da OMS que traz informações sobre a importância da adesão às vacinas.

Esse tipo de intervenção pode ser conflituosa, utilizando o controle e a restrição às informações, mesmo que para a proteção coletiva. No elo epidemiológico claro entre queda na cobertura vacinal e o ressurgimento de doenças antes eram tidas como controladas, é imprescindível a união de esforços conjuntos de todos os protagonistas envolvidos direta ou indiretamente na situação vacinal. O movimento antivacina é mais um dos atores relacionados este drama social e necessita ser abordado seriamente pelos órgãos de saúde. Na era da informação, novas estratégias precisam ser estudadas para apresentar a população, de modo acessível, que os riscos do retorno dessas mazelas podem gerar prejuízos incalculáveis para a saúde de todo o mundo (BRASIL, 2015).

\section{CONSIDERAÇÕES FINAIS}

O ressurgimento de doenças que eram tidas como controladas por programas nacionais, exibe a dificuldade de adequação da saúde para com os meios de informação atual, que perpetuam dúvidas, medos e mentiras, em notícias chamadas de fake News, que podem ter contribuído para a redução da cobertura vacinal mostrado nos dados em estudo. Os esforços pela vacinação passam por estratégias que impactem a comunidades em sua nova forma de comunicar, incentivando a vacinação e transmitindo veracidade, de forma acessível, rápida e honesta. Portanto, o estudo serve como um alerta para a importância de veicular informações corretas e que sejam de fácil acesso, visando minimizar os efeitos das notícias pregadas pelo movimento antivacina.

\section{REFERÊNCIAS}

1. BEDNARCZYK RA. Examining the "why" of vaccine hesitancy. Health Psychology: Official journal of the Division of Health Psychology, American Psychological Association, 2018; 37(4): 316-317.

2. BERNARDO A. Porque as pessoas estão tomando menos vacina. Revista Saúde. Editora Abril, 2019.

3. BRASIL. Ministério da Saúde (Org.). Entenda por que a vacinação evita doenças e salva vidas. 2018. Disponível em: <http://portalms.saude.gov.br/acoes-e-programas/vacinacao/vacine-se>. Acesso em: 29 set. 2018.

4. BRASIL. Ministério da Saúde. Programa Nacional de Imunização (Org.). Coberturas vacinais no Brasil: Período: 2010 - 2014. 2015.

5. CRUZ A. A queda da imunização no Brasil. Consensus, 2017.

6. D'ALÒ GL, et al. Frequently asked questions on seven rare adverse events following immunization. Journal Of Preventive Medicine And Hygiene, 2017;.1(58):13-26.

7. FRANÇA ISX, et al. Cobertura vacinal e mortalidade infantil em Campina Grande, PB, Brasil. Revista brasileira de enfermagem., 2009; 62(2): 258-271.

8. GASPARINI R, et al. The "urban myth" of the association between neurological disorders and vaccinations. Journal of Preventive Medicine and Hygiene, 2015; 56(1).

9. GUIMARÃES K. Vacinação em queda no Brasil preocupa autoridades por risco de surtos e epidemias de doenças fatais. BBC Brasil, 2017

10. HORNE $Z$ et al. Countering antivaccination attitudes. Proceedings Of The National Academy Of Sciences, 2015; 112(33): 10321-10324.

11. HUSSAIN A, et al. The Anti-vaccination Movement: A Regression in Modern Medicine. Cureus, 2018; $10(7)$ : e2919.

12. KUPFERSCHMIDT K. The Science of Persuasion: Vaccines save lives. But what is the most effective way to convince worried parents? AAAS, 2017; 356(6336): 366-370.

13. LAURENT-LEDRU V, et al. Civil society: A critical new advocate for vaccination in Europe. Vaccine, 2011; 29(4): 624-628.

14. LEASK J. Should we do battle with antivaccination activists? Public Health Research \& Practice, 2015; $25(2): 1$-4.

15. NEVES J. Justiça protege crianças e adolescentes contra movimento antivacinação. Portal Fiocruz, 2019. 
16. LOWE T. Como Tinseltown provocou uma crise global de saúde. Washington Examinaner, 2019.

17. PHILADELPHIA. The College of Physicians of (Org.). History of Anti-vaccination Movements. United States of America, 2018. Disponível em: <https://www.historyofvaccines.org/content/articles/history-anti-vaccinationmovements>. Acesso em: 24 set. 2018.

18. RADZIKOWSKI J, et al. The Measles Vaccination Narrative in Twitter: A Quantitative Analysis. JMIR Public Health And Surveillance, 2016; 2(1): 1-35.

19. SANTOS MA. Técnica, espaço, tempo. São Paulo: Ed. Edusp. 2008.

20. SANTOS VLC, SANTOS JE. As redes sociais digitais e sua influência na sociedade e educação contemporâneas. Holos, 2014; 30(6).

21. SATO APS. Qual a importância da hesitação vacinal na queda das coberturas vacinais no Brasil? Revista de Saúde Pública, 2018; 52 (96).

22. SUCCI RCM. Vaccine refusal: what we need to know. Jornal de Pediatria, 2017; 17(653): 1-8.

23. TUSTIN JL, et al. Internet exposure associated with canadian parents' perception of risk on childhood immunization: cross-sectional study. JMIR Public Health And Surveillance, 2018; 4(1): 7-16.

24. VASCONCELLOS-SILVA PR, et al. A sociedade de risco midiatizada, o movimento antivacinação e o risco do autismo. Ciência \& Saúde Coletiva, 2015; 20(2): 607-616. 